\title{
Sequential sharing rules for river sharing problems
}

\author{
Erik Ansink • Hans-Peter Weikard
}

Received: 11 February 2010 / Accepted: 16 December 2010 / Published online: 6 January 2011

(C) The Author(s) 2011. This article is published with open access at Springerlink.com

\begin{abstract}
We analyse the redistribution of a resource amongst agents who have claims to the resource and who are ordered linearly. A well known example of this particular situation is the river sharing problem. We exploit the linear order of agents to transform the river sharing problem to a sequence of two-agent river sharing problems. These reduced problems are mathematically equivalent to bankruptcy problems and can therefore be solved using any bankruptcy rule. Our proposed class of solutions, that we call sequential sharing rules, solves the river sharing problem. Our approach extends the bankruptcy literature to settings with a sequential structure of both the agents and the resource to be shared. In the paper, we first characterise the class of sequential sharing rules. Subsequently, we apply sequential sharing rules based on four classical bankruptcy rules, assess their properties, provide two characterisations of one specific rule, and compare sequential sharing rules with three alternative solutions to the river sharing problem.
\end{abstract}

\section{Introduction}

In this paper we analyse the redistribution of a resource amongst agents who have claims to the resource and who are ordered linearly. Our choice for this particular situation is motivated by the following two examples.

\footnotetext{
E. Ansink $(\varangle)$

Institute for Environmental Studies (IVM), VU University Amsterdam,

De Boelelaan 1087, 1081 HV Amsterdam, The Netherlands

e-mail: erikansink@gmail.com

H.-P. Weikard

Wageningen University, Wageningen, The Netherlands
} 
The first example is the distribution of intergenerational welfare (Arrow et al. 2004). The agents are the generations, ordered linearly in time. Each generation is endowed with certain resources, but also has a claim to inherit part of the resources of the previous generation. A specific problem of this kind is the climate change problem, where each generation adds to the stock of greenhouse gases, but also makes a claim to previous generations' mitigation efforts (Dasgupta et al. 1999; Weikard 2004; Davidson 2008).

The second example is the river sharing problem (Ambec and Sprumont 2002; Parrachino et al. 2006; Carraro et al. 2007; Ambec and Ehlers 2008). This is the topic of this paper. In the river sharing problem, the agents are countries (or water users in general) ordered linearly along a river. On the territory of each agent tributaries and rainfall add water to the river. This constitutes an agent's endowment of river flow. Each country also has a claim to river water. These claims can be based on any of a wide range of principles for river sharing (Wolf 1999; Daoudy 2008). Two common principles for river sharing are absolute territorial sovereignty (ATS) and absolute territorial integrity (ATI) (Salman 2007). ATS prescribes that each agent has the right to all water on his territory while ATI prescribes that each agent has the right to all upstream water. Though these extreme principles are not often invoked in practice, agents' claims are often larger than their endowments, as illustrated for instance by Egypt's large claim to water in the Nile river basin. Agents' overlapping claims to river water make water a contested resource (Ansink and Weikard 2009).

In both examples, redistribution of the resource endowments may be desirable, for instance when some agents have large endowments but only small claims (cf. Bossert and Fleurbaey 1996). We exploit the linear order of agents to determine this redistribution using an axiomatic approach. Using three very natural requirements, the order of agents allows us to transform the river sharing problem to a sequence of two-agent river sharing problems that we call reduced river sharing problems. Reduced river sharing problems are mathematically equivalent to bankruptcy problems (Aumann and Maschler 1985; Young 1987; Moulin 2002). Therefore, we can use sharing rules from the bankruptcy literature to solve these reduced river sharing problems. In each of these reduced problems, water rights are allocated to an agent and the set of his downstream neighbours. As in bankruptcy problems, our proposed class of solutionsdenoted sequential sharing rules - is based on the agents' claims. Sequential sharing rules are constructed by the recursive application of a bankruptcy rule to the sequence of reduced river sharing problems.

In a bankruptcy problem, a perfectly divisible resource (usually called the estate in this literature) is to be distributed over a set of agents who have overlapping claims. A solution to a bankruptcy problem is a sharing rule (or alternatively, a rationing scheme), that is based on the agents' claims to the resource. Various axiomatic approaches to the construction of such sharing rules have been analysed (cf. Herrero and Villar 2001; Thomson 2003).

In a river sharing problem, agents are ordered linearly, characterised by an initial resource endowment and a claim to the resource. Claims are exogenous and may be smaller or larger than an agent's endowment. As in the bankruptcy problem, we assume scarcity of the resource. River sharing problems differ from bankruptcy problems in two ways. First, there is a difference in the position of the agents. In the standard 
bankruptcy problem, all agents have equal positions. In a river sharing problem, agents are ordered linearly, reflecting the direction of river flow. Therefore, the agents' claims have a sequential structure, linking the river sharing problem to bankruptcy problems with a priority order (cf. Moulin 2000). Second, there is a difference in the initial state of the resource. In a bankruptcy problem, the resource is initially completely separated from the agents. In a river sharing problem, the resource is initially endowed to the agents. This endowment of resources links our approach to reallocation problems (cf. Fleurbaey 1994; Klaus et al. 1997). Both differences play a key role in the construction of the class of sequential sharing rules.

There are two reasons for solving river sharing problems using bankruptcy rules. ${ }^{1}$ First, as indicated above, both types of problems have the common feature that claims exceed the available resource. Moreover, the properties of bankruptcy rules are well understood, hence they can easily be put to use. The second reason is pragmatic. Many two-agent water rights disputes are solved using variants of bankruptcy rules, for instance equal sharing or sharing proportional to some objective criterion (e.g. population or the amount of irrigable land, see Wolf 1999). Often, these solutions are explicitly proposed by third parties or joint river basin committees, but they can also be the result of negotiations between the agents. This paper shows the logical extension of such sharing rules for river sharing problems with more than two agents.

This paper makes two novel contributions. First, our approach extends the bankruptcy literature to settings with a sequential (or spatial) structure of both the agents and the resource to be shared. ${ }^{2}$ Second, we provide axiomatic foundations for a class of solutions to the river sharing problem that satisfy some attractive properties.

The paper is organised as follows. In Sect. 2 we introduce the setting of the river sharing problem. In Sect. 3 the class of sequential sharing rules is characterised. In Sect. 4 we apply four sequential sharing rules, based on four classical bankruptcy rules, to a numerical example. In Sect. 5 some properties of sequential sharing rules are assessed and we provide two characterisations of one specific rule. In Sect. 6 we compare our approach to three alternative solutions to the river sharing problem. In Sect. 7 we discuss the results and conclude.

\section{The river sharing problem}

Consider an ordered set $N$ of $n \geq 2$ agents located along a river, with agent 1 the most upstream and $n$ the most downstream. Agent $i$ is upstream of $j$ whenever $i<j$. Denote by $U_{i}=\{j \in N: j<i\}$ the set of agents upstream of $i$, and denote by $D_{i}=\{j \in N: j>i\}$ the set of agents downstream of $i$. On the territory of $i$, rainfall

\footnotetext{
1 The standard approach to analyse river sharing problems is to apply non-cooperative game-theoretic models (cf. Carraro et al. 2007; Ansink and Ruijs 2008). The merit of the axiomatic approach employed in this paper is to complement, support and improve our understanding of the outcomes of these strategic models.

2 Branzei et al. (2008) also analyse bankruptcy rules in a flow network. In their approach, however, the flows are cost functions that are used to implement bankruptcy rules in a network approach. Recently, Bjørndal and Jörnsten (2010) discussed flow sharing problems as a generalisation of bankruptcy problems, a topic to which we return in Sect. 6.
} 
or inflow from tributaries increases total river flow by $e_{i} \geq 0 ; e=\left(e_{1}, \ldots, e_{n}\right)$. River inflow $e_{i}$ can be considered the endowment of $i$. This does not imply that agent $i$ has property rights to $e_{i}$. Rights are assigned as a solution to a river sharing problem, as discussed below. In addition to river inflow $e_{i}$, each agent is characterised by having a claim $c_{i} \geq 0$ to river flow; $c=\left(c_{1}, \ldots, c_{n}\right)$. We do not impose which portion of an agent's claim is directed to $e_{1}, e_{2}, \ldots$, etc.

This information suffices to define our river sharing problem.

Definition 1 (River sharing problem) A river sharing problem is a triple $\omega=$ $\langle N, e, c\rangle$, with $N$ an ordered and finite set of agents, an endowments vector $e \in \mathbb{R}_{+}^{n}$ and a claims vector $c \in \mathbb{R}_{+}^{n}$.

Denote by $x=\left(x_{1}, \ldots, x_{n}\right)$ the vector of allocated water rights, determined by a sharing rule as described below. To delineate the setting of the river sharing problem, let the total available water on the territory of agent $i$ be denoted by

$$
E_{i} \equiv e_{i}+\sum_{j \in U_{i}}\left(e_{j}-x_{j}\right) \text {. }
$$

$E_{i}$ is the sum of river inflow on the territory of $i$ and any unallocated upstream water. ${ }^{3}$ Because water is scarce, we assume that all allocated water is consumed. For the river sharing problem to be relevant, we make the following assumption.

Assumption 1 Downstream claims exceed downstream endowments at each location along the river: $c_{i}+\sum_{j \in D_{i}} c_{j} \geq e_{i}+\sum_{j \in D_{i}} e_{j}, \forall i \in N$.

This assumption implies that $c_{n} \geq e_{n}$. It assures that there is contested water throughout the river or all claims are just satisfied (see Lemma 1 below).

Denote by $\Omega$ the set of relevant river sharing problems that satisfy Assumption 1 . A sharing rule allocates water rights to each agent.

Definition 2 (Sharing rule) A sharing rule is a mapping $F: \Omega \rightarrow \mathbb{R}^{n}$ that assigns to every river sharing problem $\omega \in \Omega$ a water rights allocation vector $x=\left(x_{1}, \ldots, x_{n}\right), x \in \mathbb{R}_{+}^{n}$, such that (a) $\sum_{i \in N} x_{i}=\sum_{i \in N} e_{i}$, (b) $0 \leq x \leq c$, and (c) $x_{i} \leq E_{i}, \forall i \in N$.

The allocation of water rights to agent $i$ is $F_{i}(\omega)=x_{i}$. Requirement (a) of the sharing rule imposes efficiency: no water rights remain unallocated. Requirement (b) says that agents receive a non-negative allocation that is bounded by their claim. Requirement (c) is a feasibility constraint. Figure 1 illustrates a river sharing problem for $n=4$.

\section{Characterisation of sequential sharing rules}

Solutions from the bankruptcy literature cannot be directly applied to the river sharing problem, because the resource is distributed over the agents. The linear order of

\footnotetext{
$3 E_{i}$ depends on the allocation to upstream agents $x_{U_{i}}$. For ease of notation we do not include this allocation as an argument of $E_{i}$.
} 
Fig. 1 The river sharing problem for $n=4$; nodes are agents and arrows indicate water flows

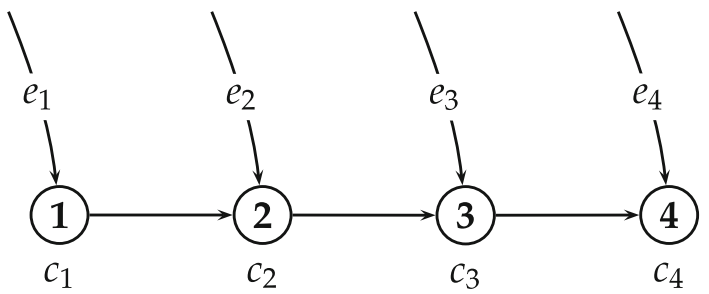

agents along the river and the unidirectionality of river flow enable us, however, to represent the river sharing problem as a sequence of reduced river sharing problems. These reduced river sharing problems are mathematically equivalent to bankruptcy problems. They can therefore be solved using bankruptcy rules. In this section we first define a class of rules for river sharing problems - called sequential sharing rulesthat follow this procedure. Then we characterise this class using three very natural axioms.

Denote by $c_{D_{i}}$ downstream excess claims that are defined as the sum of claims net of endowments of all agents downstream of $i$ :

$$
c_{D_{i}} \equiv \sum_{j \in D_{i}}\left(c_{j}-e_{j}\right) .
$$

By Assumption 1 we know that $c_{D_{i}} \geq 0, \forall i \in N \backslash n$. Consequently, the corresponding downstream endowments are $e_{D_{i}}=0, \forall i \in N$.

Using (2), a river sharing problem $\omega$ can be represented as a sequence $\left(\omega_{1}, \ldots, \omega_{n}\right)$ of reduced river sharing problems $\omega_{i}$.

Definition 3 (Reduced river sharing problem) A reduced river sharing problem is a triple $\omega_{i}=\left\langle\left\{i, D_{i}\right\},\left(E_{i}, e_{D_{i}}\right),\left(c_{i}, c_{D_{i}}\right)\right\rangle$, with two agents $i$ and $D_{i}$, endowments $E_{i}$ (recall that $e_{D_{i}}=0$ ), and a claims vector $\left(c_{i}, c_{D_{i}}\right)$.

Note that, in slight abuse of notation, we denote the second agent in the reduced river sharing problem by $D_{i}$. This set of downstream agents is treated as a single claimant. In each reduced problem $\omega_{i}$, available river flow $E_{i}$ is distributed between $i$ and $D_{i}$, where the claim of $D_{i}$ is its downstream excess claim $c_{D_{i}}$ as defined in (2). Downstream river flow is first used to (partly) satisfy downstream claims so that only claims in excess of downstream river flow can affect upstream water allocation.

A reduced river sharing problem is mathematically equivalent to a bankruptcy problem. ${ }^{4}$

Definition 4 (Bankruptcy problem) A bankruptcy problem is a triple $\psi=\langle N, E, c\rangle$, with $N$ a finite set of agents, an endowment $E \in \mathbb{R}_{+}$, and a claims vector $c \in \mathbb{R}_{+}^{n}$.

Denote by $\Psi$ the set of relevant bankruptcy problems that satisfy $\sum_{i \in N} c_{i} \geq E$. Bankruptcy rules can be applied to any reduced river sharing problem.

\footnotetext{
4 That is, if we do not attribute $E_{i}$ to one of the agents. In the concluding section we will discuss a difference in interpretation.
} 
Definition 5 (Bankruptcy rule) A bankruptcy rule is a mapping $B: \Psi \rightarrow \mathbb{R}^{n}$ that assigns to every bankruptcy problem $\psi \in \Psi$ an allocation vector $x=$ $\left(x_{1}, \ldots, x_{n}\right), x \in \mathbb{R}_{+}^{n}$, such that (a) $\sum_{i \in N} x_{i}=\sum_{i \in N} e_{i}$, (b) $0 \leq x \leq c$, and (c) for $\psi^{\prime}=\left\langle N^{\prime}, E, c\right\rangle$ where $N^{\prime}$ is any permutation of $N$, we have $B_{i}(\psi)=B_{i}\left(\psi^{\prime}\right)$.

Note that, slightly unconventional, requirement (c) of this definition imposes anonymity of the bankruptcy rule. We add this requirement to stress that any difference in allocation between upstream and downstream agents is not due to the preferential treatment of agents by a particular bankruptcy rule.

In order to solve a river sharing problem, a bankruptcy rule is applied to the sequence $\left(\omega_{1}, \ldots, \omega_{n}\right)$ of its reduced problems. Because of $(1)$, however, the reduced problems and their solutions are dependent on each other. Because $E_{1}=e_{1}$ by definition, $\omega_{1}$ is the only reduced problem whose outcome is independent of the outcome of other reduced problems. Its solution-allocating $x_{1}$ to agent 1 - determines $E_{2}$ which enables the formulation of and a solution to $\omega_{2}$, etc. More specifically, the procedure is as follows. Consider a river sharing problem $\omega$ and let $\omega_{1}=\left\langle\left\{1, D_{1}\right\},\left(E_{1}, 0\right),\left(c_{1}, c_{D_{1}}\right)\right\rangle$. Now we set $x_{1}=B_{1}\left(\omega_{1}\right)$ so that $x_{D_{1}}=E_{1}-x_{1}$ and therefore $E_{2}=e_{1}+e_{2}-x_{1}$. Subsequently, let $\omega_{2}=\left\langle\left\{2, D_{2}\right\},\left(E_{2}, 0\right),\left(c_{2}, c_{D_{2}}\right)\right\rangle$. We set $x_{2}=B_{2}\left(\omega_{2}\right)$ so that $x_{D_{2}}=E_{2}-x_{2}$ and so on.

An obvious requirement for this procedure to work is that in each reduced river sharing problem the sum of claims exceeds the available river flow so that the problem belongs to the set of relevant problems. This relevance is established in the following lemma.

Lemma 1 For any river sharing problem $\omega \in \Omega$ and under any sharing rule $F$ each reduced river sharing problem $\omega_{i}$ is a relevant problem such that the sum of claims (weakly) exceeds available water: $c_{i}+c_{D_{i}} \geq E_{i}, \forall i \in N$.

Proof The proof is by induction. The inductive hypothesis is to show that the lemma holds for $i=1$. First, notice that using (2), Assumption 1 can be rearranged to

$$
c_{i}+c_{D_{i}} \geq e_{i}, \quad \forall i \in N
$$

Now consider the first reduced problem $\omega_{1}$ of river sharing problem $\omega$. By (3) we have $c_{1}+c_{D_{1}} \geq e_{1}=E_{1}$ so that for $\omega_{1}$ claims exceed available water.

The inductive step is to show that if the lemma holds for $i$, then it also holds for $i+1$. Requirement (b) of Definition 2 is that $x \leq c$ so that $x_{D_{i}} \leq c_{D_{i}}$. Because (1) implies $E_{i+1}=e_{i+1}+x_{D_{i}}$ we have

$$
E_{i+1} \leq e_{i+1}+c_{D_{i}}
$$

Using (2) the RHS of (4) can be rewritten as $e_{i+1}+c_{D_{i}}=c_{i+1}+c_{D_{i+1}}$. This implies that $c_{i+1}+c_{D_{i+1}} \geq E_{i+1}$ so that for $\omega_{i+1}$, claims (weakly) exceed available water. This completes the proof.

Lemma 1 assures that-analogous to Assumption 1-each reduced river sharing problem is a relevant river sharing problem according to Definition 1 . Therefore, a 
sharing rule assigns to every reduced river sharing problem $\omega_{i}$ a water rights allocation vector $x=\left(x_{i}, x_{D_{i}}\right)$, such that $x_{i}+x_{D_{i}}=E_{i}$.

Given Lemma 1, the sequence of reduced problems can be solved recursively in the linear order of agents along the river. Now we are able to define sequential sharing rules.

Definition 6 (Sequential sharing rule) A sequential sharing rule for river sharing problem $\omega$ is a sharing rule $F$ that allocates to each agent the allocation provided by repeatedly applying a bankruptcy rule $B$ to its corresponding sequence of reduced river sharing problems $\left(\omega_{1}, \ldots, \omega_{n}\right)$, so that $F_{i}(\omega)=B_{i}\left(\omega_{i}\right), \forall i \in N$.

Using sequential sharing rules, the water rights allocated to each agent are equal to the allocation provided by the recursive solution of its corresponding sequence of reduced problems. Given the vectors of claims and endowments, the allocation to agent $i$ is therefore independent of the number of agents in $D_{i}$, the distribution of their claims $\left(c_{i+1}, \ldots, c_{n}\right)$ and the distribution of their endowments $\left(e_{i+1}, \ldots, e_{n}\right)$; only the difference between aggregate claims $\sum_{j \in D_{i}} c_{j}$ and endowments $\sum_{j \in D_{i}} e_{j}$ matters.

For the characterisation of sequential sharing rules, consider the following three axioms.

Only n's Excess Claim Matters: For each river sharing problem $\omega=\langle N, e, c\rangle$, and each related problem $\omega^{\prime}=\left\langle N, e^{\prime}, c^{\prime}\right\rangle$ such that $e^{\prime}=\left(e_{1}, \ldots, e_{n-1}, e_{n}^{\prime}\right)$ and $c^{\prime}=$ $\left(c_{1}, \ldots, c_{n-1}, c_{n}^{\prime}\right)$ with $e_{n}^{\prime}=0$ and $c_{n}^{\prime}=c_{n}-e_{n}$, we have $F_{i}(\omega)=F_{i}\left(\omega^{\prime}\right), \forall i \in N$.

This axiom requires that allocation of upstream contested water is independent of the part of the claim of agent $n$ that can be satisfied with the endowment of agent $n$. In other words, only $n$ 's excess claim $c_{n}-e_{n}$ is effective (by Assumption $1, c_{n}-e_{n} \geq 0$ ). This is a mild requirement, because $n$ is not confronted with any claims from downstream agents. In addition, there is no alternative use for $e_{n}$ than to allocate it to $n$; endowment $e_{n}$ is uncontested. Hence, it is very natural that $e_{n}$ is used to partially satisfy $c_{n}$.

No Advantageous Downstream Merging: For each river sharing problem $\omega=$ $\langle N, e, c\rangle$, and each related problem $\omega^{\prime}=\left\langle N^{\prime}, e^{\prime}, c^{\prime}\right\rangle$ such that $N^{\prime}=N \backslash\{n\}$ and $e^{\prime}=\left(e_{1}, \ldots, e_{n-2}, e_{n-1}^{\prime}\right)$ and $c^{\prime}=\left(c_{1}, \ldots, c_{n-2}, c_{n-1}^{\prime}\right)$, with $e_{n-1}^{\prime}=e_{n-1}+e_{n}$ and $c_{n-1}^{\prime}=c_{n-1}+c_{n}$, we have $F_{i}(\omega)=F_{i}\left(\omega^{\prime}\right), \forall i<n-2$.

This property pertains to the possibility that agents $n-1$ and $n$ consolidate their claims and endowments and present themselves as a single claimant. The axiom prescribes that the allocation to upstream agents is not affected by such behaviour. Note that the axiom is similar in spirit to the No Advantageous Merging or Splitting axiom (O’Neill 1982; Thomson 2003). ${ }^{5}$

Upstream Consistency: For each river sharing problem $\omega=\langle N, e, c\rangle$, each $i \in$ $N \backslash\{1\}$, and each related problem $\omega^{\prime}=\left\langle N^{\prime}, e^{\prime}, c^{\prime}\right\rangle$ such that $N^{\prime}=N \backslash\{1\}, c^{\prime}=$ $\left(c_{2}, \ldots, c_{n}\right)$, and $e^{\prime}=\left(e_{1}-x_{1}+e_{2}, e_{3}, \ldots, e_{n}\right)$, we have $F_{i}\left(\omega^{\prime}\right)=F_{i}(\omega)$.

This property requires that when player 1 leaves with his allocation, the truncated game gives the same allocation as the original game to the remaining players. This is

\footnotetext{
5 This axiom cannot be directly applied in our setting as we analyse problems where agents are ordered, but see Proposition 3.
} 
a natural and straightforward requirement as any excess water not allocated to agent $1, e_{1}-x_{1}$, is available to the second agent.

Jointly, these three axioms characterise the class of sequential sharing rules.

Proposition 1 A sharing rule for river sharing problem $\omega=\langle N, e, c\rangle$ satisfies Only $n$ 's Excess Claim Matters, No Advantageous Downstream Merging and Upstream Consistency if and only if it is a sequential sharing rule.

Proof First we show that a sequential sharing rule satisfies Only n's Excess Claim Matters, No Advantageous Downstream Merging and Upstream Consistency. Only $n$ 's Excess Claim Matters is satisfied by construction of the reduced problem $\omega_{i}=$ $\left\langle\left\{i, D_{i}\right\},\left(E_{i}, 0\right),\left(c_{i}, \sum_{j \in D_{i}}\left(c_{j}-e_{j}\right)\right)\right\rangle$. Obviously, $F\left(\omega_{i}\right)$ depends only on the last agent's excess claim, not on $c_{n}$ or $e_{n}$ in isolation. Hence, for any sequential sharing rule also $F(\omega)=F\left(\left\langle N,\left(e_{1}, \ldots, e_{n-1}, 0\right),\left(c_{1}, \ldots, c_{n-1}, c_{n}-e_{n}\right)\right\rangle\right)$. No Advantageous Downstream Merging is satisfied because in every reduced game $F\left(\omega_{i}\right)$ depends only on the aggregate downstream excess claim $\sum_{j \in D_{i}}\left(c_{j}-e_{j}\right)$. Downstream merging does not affect this aggregate claim. Upstream Consistency is satisfied because by (1), $E_{2}=e_{2}+e_{1}-x_{1}$ and $E_{2}$ is the relevant endowment for the truncated problem $\left\langle N \backslash\{1\},\left(c_{2}, \ldots, c_{n}\right),\left(e_{1}-x_{1}+e_{2}, e_{3}, \ldots, e_{n}\right)\right\rangle$.

Next we show that any sharing rule $F$ that satisfies Only n's Excess Claim Matters, No Advantageous Downstream Merging and Upstream Consistency is a sequential sharing rule. Consider river sharing problem $\omega=\langle N, e, c\rangle$ and its solution $F(\omega)$. To establish that $F_{1}(\omega)=F_{1}\left(\omega_{1}\right)$ we apply No Advantageous Downstream Merging to player 1 . We have $F_{1}(\omega)=F_{1}\left(\left\langle\left\{1, D_{1}\right\},\left(e_{1}, \sum_{j \in D_{1}} e_{j}\right),\left(c_{1}, \sum_{j \in D_{1}} c_{j}\right)\right\rangle\right)$. From this, by repeated application of Only n's Excess Claim Matters we have $F_{1}(\omega)=F_{1}\left(\left\langle\left\{1, D_{1}\right\},\left(e_{1}, 0\right),\left(c_{1}, \sum_{j \in D_{1}}\left(c_{j}-e_{j}\right)\right\rangle\right)=F_{1}\left(\omega_{1}\right)\right.$. To establish that $F_{2}(\omega)=F_{2}\left(\omega_{2}\right)$ we apply No Advantageous Downstream Merging to player 2. We have $F_{2}(\omega)=F_{2}\left(\left\langle\left\{1,2, D_{2}\right\},\left(e_{1}, e_{2}, \sum_{j \in D_{2}} e_{j}\right),\left(c_{1}, \sum_{j \in D_{2}} c_{j}\right)\right\rangle\right)$. From this, by repeated application of Only $n$ 's Excess Claim Matters we have $F(\omega)=$ $F\left(\left\langle\left\{1,2, D_{2}\right\},\left(e_{1}, e_{2}, 0\right),\left(c_{1}, c_{2}, \sum_{j \in D_{2}}\left(c_{j}-e_{j}\right)\right\rangle\right)\right.$. Using Upstream Consistency and $F_{1}(\omega)=x_{1}$, we know that $F_{2}(\omega)=F_{2}\left(\omega_{2}\right)$. By repeating this procedure for agents $3, \ldots, n-1$, using recursive application of Upstream Consistency, we obtain $F(\omega)=\left(F_{1}\left(\omega_{1}\right), \ldots, F_{n}\left(\omega_{n}\right)\right)$ which completes the proof.

Only n's Excess Claim Matters, No Advantageous Downstream Merging and Upstream Consistency characterise the class of sequential sharing rules. In the next sections we focus on four classical bankruptcy rules and assess some properties of their corresponding sequential sharing rules.

\section{Application}

In this section we apply four sequential sharing rules, based on four classical bankruptcy rules, to an illustrative river sharing problem. The four classical bankruptcy rules are the proportional rule, constrained equal awards, constrained equal losses and 
the Talmud rule (Herrero and Villar 2001). In our notation for two-agent problems, the definitions of the four rules are as follows.

Proportional rule $(P R O)$ : For all $\omega_{i}=\left\langle\left\{i, D_{i}\right\},\left(E_{i}, 0\right),\left(c_{i}, c_{D_{i}}\right)\right\rangle$, there exists $\lambda>0$, such that $x_{i}^{\mathrm{PRO}}=\lambda c_{i}$ and $x_{D_{i}}^{\mathrm{PRO}}=\lambda c_{D_{i}}$.

PRO assigns each agent a share of the resource in proportion to the agents' claims.

Constrained equal awards (CEA): For all $\omega_{i}=\left\langle\left\{i, D_{i}\right\},\left(E_{i}, 0\right),\left(c_{i}, c_{D_{i}}\right)\right\rangle$, there exists $\lambda>0$, such that $x_{i}^{\mathrm{CEA}}=\min \left\{c_{i}, \lambda\right\}$ and $x_{D_{i}}^{\mathrm{CEA}}=\min \left\{c_{D_{i}}, \lambda\right\}$.

CEA assigns each agent an equal share of the resource, subject to no agent receiving more than his claim.

Constrained equal losses (CEL): For all $\omega_{i}=\left\langle\left\{i, D_{i}\right\},\left(E_{i}, 0\right),\left(c_{i}, c_{D_{i}}\right)\right\rangle$, there exists $\lambda>0$, such that $x_{i}^{\mathrm{CEL}}=\max \left\{0, c_{i}-\lambda\right\}$ and $x_{D_{i}}^{\mathrm{CEL}}=\max \left\{0, c_{D_{i}}-\lambda\right\}$.

CEL assigns each agent a share of the resource such that their losses compared to their claims are equal, subject to no agent receiving a negative share.

Talmud rule $(T A L)$ : For all $\omega_{i}=\left\langle\left\{i, D_{i}\right\},\left(E_{i}, 0\right),\left(c_{i}, c_{D_{i}}\right)\right\rangle$, there exists $\lambda>0$, such that

$$
\begin{aligned}
x_{i}^{\mathrm{TAL}} & = \begin{cases}\min \left\{\frac{1}{2} c_{i}, \lambda\right\} & \text { if } E_{i} \leq \frac{1}{2}\left(c_{i}+c_{D_{i}}\right), \\
c_{i}-\min \left\{\frac{1}{2} c_{i}, \lambda\right\} & \text { otherwise, }\end{cases} \\
x_{D_{i}}^{\mathrm{TAL}} & = \begin{cases}\min \left\{\frac{1}{2} c_{D_{i}}, \lambda\right\} & \text { if } E_{i} \leq \frac{1}{2}\left(c_{i}+c_{D_{i}}\right), \\
c_{D_{i}}-\min \left\{\frac{1}{2} c_{D_{i}}, \lambda\right\} & \text { otherwise. }\end{cases}
\end{aligned}
$$

TAL assigns each agent his uncontested share of the resource and divides the contested part equally.

As discussed in Sect. 1, many two-agent water rights disputes are solved using variants of bankruptcy rules. The practice of sharing water proportional to some objective criterion corresponds to the application of PRO in case that the agents' claims are based on the same principle for water sharing. CEA corresponds to equal sharing when claims are sufficiently high, whereas CEL corresponds to equal sharing when claims are equal. The principles of ATS and ATI are approximated in situations where the upstream agent has either a very high or very low claim compared to the downstream agent, for any of these four classical rules.

To illustrate how a solution to the river sharing problem is calculated, Table 1 shows the steps to the solution to a river sharing problem for $n=4$ and using PRO. In this example, the values chosen for $e$ and $c$ illustrate a river sharing problem in which the major share of river flow originates on the territory of agent 1 , while the largest claim is made by agent 4 .

In Table 1, the river sharing problem is described by the first three columns that represent the set of agents $N$ and the vectors $e$ and $c$. The first reduced river sharing problem is $\omega_{1}=\left\langle\left\{1, D_{1}\right\},\left(E_{1}, 0\right),\left(c_{1}, c_{D_{1}}\right)\right\rangle$, with two agents, 1 and $D_{1}$, who have claims $\left(c_{1}, c_{D_{1}}\right)$, to the resource $E_{1} . E_{1}=80$ is calculated using (1) and $c_{D_{1}}=90$ is calculated using (2). The solution using PRO yields $x=(29,51)$. This solution (i.e. $\left.x_{D_{1}}=51\right)$ is used as input for the second reduced river sharing problem $\omega_{2}$ and so on. The last column of Table 1 provides values for $p_{i} \equiv x_{i} / c_{i}$ : the proportion of agent $i$ 's claim that is allocated to him. This column shows that the sequential sharing rule based on PRO generates a solution with different values for $p_{i}$. In a bankruptcy problem, 
Table 1 Example of the calculation of $x$ using PRO

\begin{tabular}{|c|c|c|c|c|c|c|c|c|c|c|}
\hline$i$ & $e_{i}$ & $c_{i}$ & $c_{D_{i}}$ & $\Rightarrow$ & $E_{i}$ & $\Rightarrow$ & $x_{i}^{\mathrm{PRO}}$ & $x_{D_{i}}^{\mathrm{PRO}}$ & $\Rightarrow$ & $p_{i}^{\mathrm{PRO}}$ \\
\hline 1 & 80 & 50 & 90 & & 80 & & 29 & 51 & & 0.57 \\
\hline 2 & 10 & 10 & 90 & & 61 & & 6 & 55 & & 0.61 \\
\hline 3 & 10 & 20 & 80 & & 65 & & 13 & 52 & & 0.65 \\
\hline 4 & 10 & 90 & - & & 62 & & 62 & - & & 0.69 \\
\hline
\end{tabular}

Table 2 Comparison of solutions for three different combinations of claims and endowments of river flow

\begin{tabular}{|c|c|c|c|c|c|c|c|c|c|c|c|}
\hline$i$ & $e_{i}$ & $c_{i}$ & $\Rightarrow$ & $x_{i}^{\text {PRO }}$ & $p_{i}^{\mathrm{PRO}}$ & $x_{i}^{\mathrm{CEA}}$ & $p_{i}^{\text {CEA }}$ & $x_{i}^{\mathrm{CEL}}$ & $p_{i}^{\text {CEL }}$ & $x_{i}^{\mathrm{TAL}}$ & $p_{i}^{\mathrm{TAL}}$ \\
\hline \multicolumn{12}{|c|}{ Case 1} \\
\hline 1 & 80 & 50 & & 29 & 0.57 & 40 & 0.80 & 20 & 0.40 & 25 & 0.50 \\
\hline 2 & 10 & 10 & & 6 & 0.61 & 10 & 1.00 & 0 & 0.00 & 5 & 0.50 \\
\hline 3 & 10 & 20 & & 13 & 0.65 & 20 & 1.00 & 10 & 0.50 & 10 & 0.50 \\
\hline 4 & 10 & 90 & & 62 & 0.69 & 40 & 0.44 & 80 & 0.89 & 70 & 0.78 \\
\hline \multicolumn{12}{|c|}{ Case 2} \\
\hline 1 & 80 & 50 & & 25 & 0.50 & 40 & 0.80 & 10 & 0.20 & 25 & 0.50 \\
\hline 2 & 10 & 30 & & 16 & 0.54 & 25 & 0.83 & 10 & 0.33 & 15 & 0.50 \\
\hline 3 & 10 & 20 & & 12 & 0.59 & 18 & 0.88 & 10 & 0.50 & 10 & 0.50 \\
\hline 4 & 10 & 90 & & 57 & 0.63 & 28 & 0.31 & 80 & 0.89 & 60 & 0.67 \\
\hline \multicolumn{12}{|c|}{ Case 3} \\
\hline 1 & 80 & 50 & & 33 & 0.67 & 40 & 0.80 & 30 & 0.60 & 30 & 0.60 \\
\hline 2 & 30 & 10 & & 8 & 0.77 & 10 & 1.00 & 0 & 0.00 & 5 & 0.50 \\
\hline 3 & 10 & 20 & & 16 & 0.79 & 20 & 1.00 & 15 & 0.75 & 13 & 0.63 \\
\hline 4 & 10 & 90 & & 73 & 0.81 & 60 & 0.67 & 85 & 0.94 & 83 & 0.92 \\
\hline
\end{tabular}

PRO would yield a constant value for $p_{i}$. This difference illustrates that accounting for the linear order of agents and their endowments indeed affects the solution to the river sharing problem.

Table 2 continues on the example given in Table 1 by comparing solutions for three different combinations of claims and endowments of river flow, for the four rules described above. It illustrates how changes in claims or endowments affect the different solutions. In case 2 of Table 2, $c_{2}$ increases from 10 to 30 compared with case 1 . This increase in claims of agent 2 causes an increase in $x_{2}$, as illustrated by PRO $(6 \rightarrow 16)$, CEA $(10 \rightarrow 25)$, CEL $(0 \rightarrow 10)$, and TAL $(5 \rightarrow 15)$. This Claims Monotonicity property is further examined in Sect. 5 . In case 3 of Table $2, e_{2}$ increases from 10 to 30 compared with case 1 . This increase in endowment of agent 2 causes an increase in $x$ for all agents, as illustrated by PRO $((29,6,13,62) \rightarrow(33,8,16,73))$, and can be verified for the other three rules too. This Resource Monotonicity property is also further examined in Sect. 5 . 


\section{Properties}

In this section we first assess the properties of sequential sharing rules, focusing on the four rules introduced in the previous section. Subsequently we provide two characterisation results for the sequential river sharing rule based on PRO.

For the assessment of properties, we consider two monotonicity properties and two of the characterising properties of the class of priority rules used by Moulin (2000). When a bankruptcy rule satisfies a property, this does not necessarily imply that its corresponding sequential sharing rule also satisfies this property. For some properties, however, the implication does hold. Some of these are appealing properties for the setting of a river sharing problem, including the following two monotonicity properties. Note that all properties in this section are first defined in their standard form for bankruptcy problems and subsequently in their corresponding form for river sharing problems, indicated by ${ }^{\star}$.

Claims monotonicity: For each bankruptcy problem $\psi=\langle N, E, c\rangle$, each $i \in N$, and each related problem $\psi^{\prime}=\left\langle N, E, c_{i}^{\prime}, c_{-i}\right\rangle$ such that $c_{i}^{\prime}>c_{i}$, we have $B_{i}\left(\psi^{\prime}\right) \geq$ $B_{i}(\psi)$.

Claims monotonicity $^{\star}$ : For each river sharing problem $\omega=\langle N, e, c\rangle$, each $i \in N$, and each related problem $\omega^{\prime}=\left\langle N, e, c_{i}^{\prime}, c_{-i}\right\rangle$ such that $c_{i}^{\prime}>c_{i}$, we have $F_{i}\left(\omega^{\prime}\right) \geq$ $F_{i}(\omega)$.

This property says that any agent $i$ should not be worse off with a larger claim.

Resource monotonicity: For each bankruptcy problem $\psi=\langle N, E, c\rangle$, each $i \in N$, and each related problem $\psi^{\prime}=\left\langle N, E^{\prime}, c\right\rangle$ such that $E^{\prime} \geq E$, we have $B\left(\psi^{\prime}\right) \geq B(\psi)$.

Resource monotonicity ${ }^{\star}$ : For each river sharing problem $\omega=\langle N, e, c\rangle$, each $i \in N$, and each related problem $\omega^{\prime}=\left\langle N, e_{i}^{\prime}, e_{-i}, c\right\rangle$ such that $e_{i}^{\prime} \geq e_{i}$, we have $F\left(\omega^{\prime}\right) \geq$ $F(\omega)$.

This property says that no agent should be worse off when some agent has a larger endowment. No agent loses regardless of his position along the river.

Moulin (2000) characterises a class of priority rules for bankruptcy problems with a priority order, which is related to our approach (see Sect. 6.2). The four characterising properties that he employs are Upper Composition, Lower Composition, Scale Invariance and Consistency. The first two of these are difficult to re-define for use in the river sharing problem. Scale Invariance and Consistency can be re-defined and we will see that Consistency ${ }^{\star}$ can be satisfied, while Scale Invariance ${ }^{\star}$ is satisfied by sequential sharing rules that are based on any bankruptcy rule that satisfies Scale Invariance.

Scale invariance: For each bankruptcy problem $\psi=\langle N, E, c\rangle$, each $i \in N$, all $\lambda \geq 0$, and each related problem $\psi^{\prime}=\langle N, \lambda E, \lambda c\rangle$, we have $B\left(\psi^{\prime}\right)=\lambda B(\psi)$.

Scale invariance $e^{\star}$. For each river sharing problem $\omega=\langle N, e, c\rangle$, each $i \in N$, all $\lambda \geq 0$, and each related problem $\omega^{\prime}=\langle N, \lambda e, \lambda c\rangle$, we have $F\left(\omega^{\prime}\right)=\lambda F(\omega)$.

This property says that a rescaling of endowments and claims (or a change of the unit in which they are measured) does not affect the solution.

Consistency: For each bankruptcy problem $\psi=\langle N, E, c\rangle$, each $i, j \in N, i \neq j$, and each related problem $\psi^{\prime}=\left\langle N \backslash\{j\}, E-B_{j}(\langle N, E, c\rangle), c_{-j}\right\rangle$, we have $B_{i}\left(\psi^{\prime}\right)=$ $B_{i}(\psi)$. 
This property says that agents receive the same allocation whether or not a subset of $N$ has left with their allocation. The definition of Consistency ${ }^{\star}$ requires some explanation. Following Moulin (2000), let the leaving subset be a single agent $j \in N$. Denote by $\omega$ the river sharing problem including $j$ and denote by $\omega^{\prime}$ the river sharing problem where $j$ has left. Agent $j$ leaves by eliminating the $j$ th element from both the set of players and the claims vector. Because agent $j$ leaves with his allocation $x_{j}=F_{j}(\omega)$, this amount has to be deducted from the endowments vector $e$. The problem is to find a suitable new endowments vector $e^{\prime}$ that satisfies the efficiency and feasibility requirements of Definition 2. The vector difference $e-e^{\prime}$ can then be regarded as the contribution of each agent's endowment to the allocation of water rights to agent $j$. Formally:

Consistency $^{\star}$ : For each river sharing problem $\omega=\langle N, e, c\rangle$, each $i, j \in N, i \neq$ $j$, and each related problem $\omega^{\prime}=\left\langle N^{\prime}, e^{\prime}, c^{\prime}\right\rangle$ such that $N^{\prime}=N \backslash\{j\}, c^{\prime}=c \backslash$ $\left\{c_{j}\right\}$, and $e^{\prime}=\left(e_{1}^{\prime}, \ldots, e_{j-1}^{\prime}, e_{j+1}^{\prime}, \ldots, e_{n}^{\prime}\right)$, with $\sum_{i \leq k}\left(e_{i}^{\prime}-e_{i}\right) \leq 0 \forall k<j$ and $\sum_{k \in N^{\prime}}\left(e_{k}^{\prime}-e_{k}\right)=e_{j}-F_{j}(\omega)$, we have $F_{i}\left(\omega^{\prime}\right)=F_{i}(\omega)$.

Note that Consistency ${ }^{\star}$ differs from Upstream Consistency introduced in Sect. 3 in that it applies to any agent in the river, not just the upstream agent.

In order to introduce the next proposition we need one additional property. This is the Linked Monotonicity property, which is the dual of Claims Monotonicity (MorenoTernero and Villar 2006):

Linked Monotonicity: For each bankruptcy problem $\psi=\langle N, E, c\rangle$, each $i \in$ $N$, each $\alpha \in R_{+}$, and a related problem $\psi^{\prime}=\left\langle N, E+\alpha,\left(c_{i}+\alpha, c_{-i}\right)\right\rangle$, we have $B_{i}\left(\psi^{\prime}\right)-B_{i}(\psi) \leq \alpha$.

This property says that if an agent's claim and the resource increase by the same amount $\alpha$, then this agent's allocation should not increase by more than $\alpha$. The following proposition covers the axioms discussed so far in this section.

Proposition 2 The following relations between the properties of bankruptcy rules and their corresponding sequential sharing rules hold:

(a) If a bankruptcy rule satisfies Claims Monotonicity and Resource Monotonicity, then its corresponding sequential sharing rule satisfies Claims Monotonicity ${ }^{\star}$.

(b) If a bankruptcy rule satisfies Claims Monotonicity, Resource Monotonicity and Linked Monotonicity, then its corresponding sequential sharing rule satisfies Resource Monotonicity .

(c) If a bankruptcy rule satisfies Scale Invariance, then its corresponding sequential sharing rule satisfies Scale Invariance ${ }^{\star}$.

(d) If a bankruptcy rule satisfies Claims Monotonicity and Resource Monotonicity, then there exists an endowments vector $e^{\prime}$ such that its corresponding sequential sharing rule satisfies Consistency ${ }^{\star}$.

Proof See Appendix.

Recall that when a rule satisfies a property, its dual rule satisfies its dual property. Because PRO and TAL are self-dual and CEA and CEL are duals of each other, and all satisfy Claims Monotonicity, we know that they all satisfy its dual property, Linked 
Monotonicity. Because PRO, CEA, CEL and TAL also satisfy Resource Monotonicity and Scale Invariance (Moulin 2002; Thomson 2003), Proposition 2 leads to the following corollary.

Corollary Sequential sharing rules based on PRO, CEA, CEL and TAL satisfy Claims Monotonicity $^{\star}$, Resource Monotonicity ${ }^{\star}$, Scale Invariance ${ }^{\star}$ and Consistency ${ }^{\star}$ (for some feasible and efficient endowment vector $e^{\prime}$ ).

Note that Proposition 2 implies that to satisfy Consistency ${ }^{\star}$, a sequential sharing rule need not be based on a bankruptcy rule that satisfies Consistency. The construction of sequential sharing rules assures that every bankruptcy rule that satisfies Claims Monotonicity and Resource Monotonicity, has a corresponding sequential sharing rule that satisfies Consistency ${ }^{\star}$ for some feasible and efficient endowments vector $e^{\prime}$.

In addition to the standard bankruptcy properties, the structure of the river allows to identify additional properties, tailored to this structure. One such property relates to an agent's position in the order of agents and how this affects his allocation.

Location Monotonicity: For each river sharing problem $\omega=\langle N, e, c\rangle$ and each $i, j \in N$ such that $i<j$, if $c_{i}=c_{j}$ then $F_{i}(\omega) \leq F_{j}(\omega)$.

Inspired by the ATI principle discussed in Sect. 1, this property says that if two agents $i, j \in N$ with $i<j$ have equal claims, then $i$ should not obtain more than $j$. This property implies that, given equal claims, downstream agents receive a weakly larger proportion of their claims than upstream agents. Note that, due to unidirectional river flow, a reverse property saying that upstream agents receive a larger allocation may be infeasible.

Another property relates sequential sharing rules to bankruptcy rules for cases where this is applicable.

Bankruptcy equivalence: Consider a sequential sharing rule $F$ based on bankruptcy rule $B$. For each river sharing problem $\omega=\langle N, e, c\rangle$ such that $e_{i}=0, \forall i>1$, i.e. $e=\left(e_{1}, 0, \ldots, 0\right)$, and each related bankruptcy problem $\psi=\left\langle N, e_{1}, c\right\rangle$, we have $F_{i}(\omega)=B_{i}(\psi), \forall i \in N$.

This property says that when all water is located at the source of the river, then the allocation provided by the sequential sharing rule is equivalent to the allocation provided by direct application of the bankruptcy rule it is based on. An implication of this property is that any differences in allocation between sequential sharing rules and the bankruptcy rules they are based on, must be due to individual endowments, not purely to the order of agents.

Using the above properties, we provide two characterisations of the sequential sharing rule based on PRO.

\section{Proposition 3}

(a) A sharing rule for a river sharing problem satisfies Only n's Excess Claim Matters, No Advantageous Downstream Merging, Upstream Consistency and Location Monotonicity if and only if it is the sequential sharing rule based on PRO.

(b) A sharing rule for a river sharing problem satisfies Only n's Excess Claim Matters, No Advantageous Downstream Merging, Upstream Consistency and Bankruptcy Equivalence if and only if it is the sequential sharing rule based on PRO. 
Proof See Appendix.

This proposition presents two characterisations based on adding just one additional constraint to the class of sequential sharing rules. These constraints are based on two intuitive properties for the case of river sharing. In part (a) of Proposition 3, this property is that downstream agents receive larger proportions of their claims. In part (b) this property is that the order of agents is irrelevant for the solution in cases where river sharing is directly equivalent to bankruptcy. Note that the two properties are conceptually distinct as Location Monotonicity stresses the importance of the agents' order, while Bankruptcy Equivalence limits the importance of this order. Given this conceptual difference, it is quite remarkable that the two properties lead to the same river sharing rule.

\section{Comparison to three alternative solutions}

In this section, we compare our solution to three alternative solutions that can be applied to river sharing problems. The first of these applies bankruptcy rules directly to river sharing problems, while treating endowments and the linear order as a feasibility constraint. The second solution is similar in spirit to the class of priority rules constructed by Moulin (2000). The third solution is the one proposed by Ambec and Sprumont (2002).

Although each of these solutions possesses some attractive features, they also have disadvantages compared to the approach presented in this paper. The first solution does not allow for differential treatment of agents that have equal claims but different endowments. The second solution strongly favours upstream agents, while the third solution strongly favours downstream agents.

\subsection{Constrained direct application of bankruptcy rules}

Constrained direct application of bankruptcy rules treats both the linear order of agents and their individual endowments as constraints to the application of bankruptcy rules to a river sharing problem. This approach is an attractive solution in the sense that it treats the river sharing problem as a bankruptcy problem to the largest extent possible. It is used by İlkiliç and Kayı (2009), who model allocation rules in a network structure (see also Bergantiños and Sanchez 2002).

For example, directly applying CEA to the river sharing problem would give every agent an equal allocation, constrained only by their claim and by the feasibility of this allocation due to location and endowments. If feasible, two agents with equal claims therefore receive the same water allocation, irrespective of their location in the basin. Because the order of agents and their endowments are treated as a feasibility constraint only, this approach preserves Equal Treatment of Equals when possible, and ignores the differences in location of the agents.

Using the class of sequential sharing rules proposed in this paper, the Equal Treatment of Equals property is not necessarily satisfied. Two agents with equal claims and endowments may end up with different allocations, even if an equal allocation 
would be feasible. This difference is driven by the agents' position in the linear order of agents and depends on the sequential sharing rule that is applied. With sequential sharing rules, the position in the linear order does not just constrain the set of possible solutions, but assigns significance to both location and individual endowments of water.

\subsection{Priority rule in the spirit of Moulin (2000)}

As discussed in Sect. 5, the class of priority rules constructed by Moulin (2000), is related to our approach. In fact, the bankruptcy problem studied in Moulin (2000), including an ordered set of agents, is a special case of the river sharing problem. The ordering of agents is according to a complete, transitive, and antisymmetric binary relation, which is equivalent to the linear order in our approach. In our notation, the priority rules satisfy:

$$
\forall i, j \in N \text { with } i<j \text {, if } x_{j}>0 \text {, then } x_{i}=c_{i} .
$$

In words, priority rules allocate water rights to upstream agents until their claim is met in full, before the next agent is served.

Again, as in the previous approach, we have to treat the endowments and linear order of the agents as a feasibility constraint. Hence, when $c_{i}>E_{i}$, agent $j=i+1$ is allocated a positive amount of water rights only when $e_{j}$ is positive. This approach is an extreme rule in the sense that it strongly favours upstream agents over downstream agents.

\subsection{Sharing a river based on Ambec and Sprumont (2002)}

Recently, Ambec and Sprumont (2002) proposed an axiomatic solution that is based on ATS and ATI, as discussed in Sect. 1. These two principles are used as a lower bound and aspiration upper bound to the welfare of a coalition of agents, with welfare originating from water and side payments. Ambec and Sprumont (2002) show that there is a unique welfare distribution that provides a compromise between these two principles: water is allocated such that each agent's welfare equals his marginal contribution to a coalition composed of all upstream agents (see also Herings et al. 2007). Note that this so-called downstream incremental distribution is in terms of welfare while we follow the bankruptcy literature by having a solution in terms of the resources to be distributed.

Comparison of the downstream incremental distribution with the class of sequential sharing rules is possible when we consider a recent extension of Ambec and Sprumont (2002) to the case of satiable agents. Ambec and Ehlers (2008) model the river sharing game for the case where each agent has a single-peaked preference function over water and show that the downstream incremental distribution extends to this setting. The bliss points of these functions can be interpreted as the agents' claims. If we further assume that agents' marginal benefits are identical and constant up to their bliss 
point, ${ }^{6}$ then the solution proposed by Ambec and Sprumont (2002) and Ambec and Ehlers (2008) falls in the class of sequential sharing rules. In fact, it is rather extreme by allocating water such that $x_{i}=\min \left\{e_{i}, c_{i}\right\}, \forall i \in N$. This solution allocates to each agent the rights to his own endowment, constrained only by his claim. Note, though, that this rule violates the anonymity requirement of Definition 5 and it may also violate the efficiency requirement of Definition 2.

This approach may be an attractive compromise of ATS and ATI but we question its applicability for two reasons. First, Ambec and Sprumont (2002) find a solution to the river sharing problem using a combination of lower and upper bounds to welfare. Uniqueness of this solution follows by construction because of the implicit assumption that lower and upper bounds coincide for the most upstream agent. In other words, it is assumed that the most upstream agent does not aspire a higher welfare level than what he can secure himself. This assumption is driving the solution. Second, the solution by Ambec and Sprumont (2002) assigns all gains from cooperation to downstream agents which is not very convincing, as noted by Van den Brink et al. (2007), Houba (2008) and Khmelnitskaya (2010).

\section{Discussion and conclusion}

As indicated in footnote 4, a remaining issue to discuss is whether a reduced river sharing problem, although mathematically equivalent to a bankruptcy problem, can indeed be interpreted as such. The answer to this question depends on the interpretation of $E_{i}$, the resource that is to be distributed between $i$ and $D_{i}$. In a bankruptcy problem, the resource is separated from the agents. In a reduced river sharing problem, $E_{i}$ is the river flow available to agent $i$. If we do not consider claims, this endowment could be interpreted as agent $i$ 's "property rights" (as in the Walrasian framework and as in the ATS principle, see Sect. 1 ). The redistribution of water is then equivalent to the redistribution of the property rights to water.

In our interpretation, overlapping claims imply that endowments do not constitute property rights. Thus, a sharing rule is needed to introduce such rights in the first place. $E_{i}$ is not interpreted as a property right, but as a resource whose level may influence the solution to a river sharing problem, depending on the sharing rule used. In this case, $E_{i}$ is separated from the agents and, hence, a reduced river sharing problem is fully equivalent to a bankruptcy problem. Although this interpretation gives additional support to the use of sequential sharing rules, we do not claim this interpretation to be more convincing than the alternative. We leave it to the reader to judge the merits of both interpretations.

In this paper we analyse a river sharing problem with linearly ordered agents who have resource endowments and claims to this resource. We construct and characterise the class of sequential sharing rules by transforming the river sharing problem to a sequence of reduced river sharing problems. These reduced problems are mathematically equivalent to bankruptcy problems and can therefore be solved using bankruptcy rules. This approach for solving river sharing problems contrasts with alternative

\footnotetext{
6 Ambec and Ehlers (2008) assume strictly increasing and strictly concave benefits of water use.
} 
approaches by allowing agents' position in the order of agents and their endowment to play an important role in the solution. A solution to a river sharing problem is determined by the combination of endowments and claims and the selected bankruptcy rule. $^{7}$

The results of this paper can be readily adopted for application in negotiations on national or international river sharing problems. The approach to be followed is to jointly agree on a bankruptcy rule to allocate water rights to the most upstream agent, who then leaves the negotiation table with his allocation. The same rule is then used sequentially to allocate water rights to the other agents.

A remaining question is whether this negotiation procedure has any credible noncooperative foundations. The $n$-player "sequential share bargaining" procedure, proposed by Herings and Predtetchinski (2007) appears to be a promising approach. Sequential share bargaining is an $n$-player extension of the Rubinstein-Ståhl bargaining model, in which the players' shares are determined sequentially according to a fixed order, and require unanimous agreement. Its resemblance to sequential sharing rules is apparent. A complete analysis of this implementation, however, is left for future work.

\section{Appendix: Proofs}

\section{Proof of Proposition 2}

Proof We prove each part of the proposition separately.

\section{(a) Claims Monotonicity}

We have to prove that Claims Monotonicity and Resource Monotonicity of a bankruptcy rule imply Claims Monotonicity ${ }^{\star}$ of its corresponding sequential sharing rule.

Consider a river sharing problem $\omega=\langle N, e, c\rangle$, and a related problem $\omega^{\prime}=$ $\left\langle N, e,\left(c_{i}^{\prime}, c_{-i}\right)\right\rangle$ such that $c_{i}^{\prime}>c_{i}$.

If $i=1$, then by Claims Monotonicity we have $x_{1}^{\prime} \geq x_{1}$.

If $i>1$, then in any reduced problem $\omega_{j}^{\prime}$ with $j<i$, we have $c_{D_{j}}^{\prime}=c_{D_{j}}+c_{i}^{\prime}-c_{i}>$ $c_{D_{j}}$. Note that, because $E_{i}=E_{i-1}+e_{i}-x_{i-1}$ and $E_{i-1}=x_{i-1}+x_{D_{i-1}}$, we can rewrite (1) as

$$
E_{i}=e_{i}+x_{D_{i-1}} \text {. }
$$

We proceed in two steps.

\footnotetext{
7 Two related approaches are the following. Goetz et al. (2008) apply sequential sharing rules to irrigation water allocation. The domain of their paper is different, however, as they focus on strategy-proof rules for situations with single-peaked preferences and, unlike Klaus et al. (1997), no initial endowments. Coram (2006) implements a sequential bidding game to allocate water. This approach also assigns an important role to agents' endowments and their location in the river, but its scope is clearly different from ours.
} 
Step (i) In reduced problem $\omega_{1}$ we have $c_{D_{1}}^{\prime}>c_{D_{1}}$. By Claims Monotonicity this implies $x_{D_{1}}^{\prime} \geq x_{D_{1}}$, and by (A1) we obtain $E_{2}^{\prime} \geq E_{2}$.

Step (ii) In reduced problem $\omega_{2}$ we have $c_{D_{2}}^{\prime}>c_{D_{2}}$ and $E_{2}^{\prime} \geq E_{2}$. By Claims Monotonicity and Resource Monotonicity jointly this implies $x_{D_{2}}^{\prime} \geq x_{D_{2}}$ and by (A1) we obtain $E_{3}^{\prime} \geq E_{3}$.

Step (ii) can be repeated so that for all $j<i$, we have $x_{D_{j}}^{\prime} \geq x_{D_{j}}$. By (A1) we obtain $E_{i}^{\prime} \geq E_{i}$. In reduced problem $\omega_{i}$ we now have $c_{i}^{\prime}>c_{i}$ and $E_{i}^{\prime} \geq E_{i}$. By Claims Monotonicity and Resource Monotonicity jointly this implies $x_{i}^{\prime} \geq x_{i}$. It follows that $c_{i}^{\prime}>c_{i} \Rightarrow F_{i}\left(\omega^{\prime}\right) \geq F_{i}(\omega)$.

\section{(b) Resource Monotonicity ${ }^{\star}$.}

We have to prove that Claims Monotonicity, Resource Monotonicity and Linked Monotonicity of a bankruptcy rule imply Resource Monotonicity ${ }^{\star}$ of its corresponding sequential sharing rule.

Consider a river sharing problem $\omega=\langle N, e, c\rangle$ and a related problem $\omega^{\prime}=$ $\left\langle N,\left(e_{i}^{\prime}, e_{-i}\right), c\right\rangle$ such that $e_{i}^{\prime} \geq e_{i}$. We proceed in four steps:

(i) we first prove that $E_{j}^{\prime} \leq E_{j} \forall j<i$ with $E_{j}-E_{j}^{\prime} \leq e_{i}^{\prime}-e_{i}$,

(ii) we then prove that $E_{i}^{\prime} \geq E_{i}$ with $E_{i}^{\prime}-E_{i} \leq e_{i}^{\prime}-e_{i}$. Subsequently, we use (i) and (ii) to prove that

(iii) $x_{j}^{\prime} \geq x_{j}$ for all $j \geq i$, and

(iv) $x_{j}^{\prime} \geq x_{j}$ for all $j<i$.

Step (i) In any reduced problem $\omega_{j}^{\prime}$ with $j<i$, we have $c_{D_{j}}^{\prime}=c_{D_{j}}-e_{i}^{\prime}+$ $e_{i} \leq c_{D_{j}}$. By Linked Monotonicity and Resource Monotonicity, we have $x_{D_{1}}-x_{D_{1}}^{\prime} \leq c_{D_{1}}-c_{D_{1}}^{\prime}=e_{i}^{\prime}-e_{i}$ and by (A1) we obtain $E_{2}-E_{2}^{\prime}=$ $x_{D_{1}}-x_{D_{1}}^{\prime} \leq e_{i}^{\prime}-e_{i}$. Again, by Linked Monotonicity and Resource Monotonicity, we have $x_{D_{2}}-x_{D_{2}}^{\prime} \leq c_{D_{2}}-c_{D_{2}}^{\prime}=e_{i}^{\prime}-e_{i}$ and by (A1) we obtain $E_{3}-E_{3}^{\prime}=x_{D_{2}}-x_{D_{2}}^{\prime} \leq e_{i}^{\prime}-e_{i}$. This argument can be repeated to find that $E_{j}^{\prime} \leq E_{j} \forall j<i$, with $E_{j}-E_{j}^{\prime} \leq e_{i}^{\prime}-e_{i}$.

Step (ii) From step (i) we have obtained that $x_{D_{i-1}}-x_{D_{i-1}}^{\prime} \leq c_{D_{i-1}}-c_{D_{i-1}}^{\prime}=$ $e_{i}^{\prime}-e_{i}$, which by rearrangement gives $x_{D_{i-1}}^{\prime} \geq x_{D_{i-1}}+e_{i}-e_{i}^{\prime}$. By substituting this inequality into (A1) we obtain

$$
\begin{aligned}
E_{i}^{\prime} & =e_{i}^{\prime}+x_{D_{i-1}}^{\prime} \\
& \geq e_{i}^{\prime}+x_{D_{i-1}}+e_{i}-e_{i}^{\prime} \\
& =x_{D_{i-1}}+e_{i} \\
& =E_{i} .
\end{aligned}
$$

Hence $E_{i}^{\prime} \geq E_{i}$, and because $x_{D_{i-1}}-x_{D_{i-1}}^{\prime} \leq e_{i}^{\prime}-e_{i}$ we know that $E_{i}^{\prime}-E_{i} \leq e_{i}^{\prime}-e_{i}$.

Step (iii) We now establish that $x_{j}^{\prime} \geq x_{j}$ for all $j \geq i$. Consider reduced problems $\omega_{i}$ and $\omega_{i}^{\prime}$. These problems are equal in terms of claims because 
$c_{i}^{\prime}=c_{i}$ and $c_{D_{i}}^{\prime}=c_{D_{i}}$. They differ, however, in resources as we have just established that $E_{i}^{\prime} \geq E_{i}$. Hence, by Resource Monotonicity $x_{i}^{\prime} \geq x_{i}$ and $x_{D_{i}}^{\prime} \geq x_{D_{i}}$, and by (A1) we obtain $E_{i+1}^{\prime} \geq E_{i+1}$. This argument can be repeated to find that $x_{j}^{\prime} \geq x_{j}, \forall j \geq i$.

Step (iv) The last step is to establish that $x_{j}^{\prime} \geq x_{j}$ for all $j<i$. Because in step (ii) we have shown that $E_{i}^{\prime} \geq E_{i}$ with $E_{i}^{\prime}-E_{i} \leq e_{i}^{\prime}-e_{i}$, and because of the efficiency requirement in Definition 2 , we know that $0 \leq \sum_{j=1}^{i}\left(x_{j}^{\prime}-x_{j}\right) \leq$ $e_{i}^{\prime}-e_{i}$. In words, agents upstream of $i$ divide a surplus weakly smaller than $e_{i}^{\prime}-e_{i}$. The question is now how this surplus is divided. Writing out (1), we have

$$
E_{j}=E_{i}-e_{i}+x_{j}-\sum_{k=j+1}^{i-1}\left(e_{k}-x_{k}\right)
$$

Using $E_{j}^{\prime} \leq E_{j}$ from step (i) by substitution:

$$
\begin{gathered}
E_{i}^{\prime}-e_{i}^{\prime}+x_{j}^{\prime}-\sum_{k=j+1}^{i-1}\left(e_{k}^{\prime}-x_{k}^{\prime}\right) \leq E_{i}-e_{i}+x_{j}-\sum_{k=j+1}^{i-1}\left(e_{k}-x_{k}\right) \\
\Rightarrow\left(E_{i}^{\prime}-E_{i}\right)-\left(e_{i}^{\prime}-e_{i}\right) \leq \sum_{k=j}^{i-1}\left(x_{k}-x_{k}^{\prime}\right) \quad\left(\text { as } e_{k}^{\prime}=e_{k}\right) \\
\Rightarrow \sum_{k=j}^{i-1}\left(x_{k}^{\prime}-x_{k}\right) \leq\left(e_{i}^{\prime}-e_{i}\right)-\left(E_{i}^{\prime}-E_{i}\right),
\end{gathered}
$$

where the RHS denotes the surplus to be divided and the LHS is the summed difference in allocations from agent $j$ downstream to $i-1$.

For $j=1$ we can now establish that, by efficiency, (A2) holds with equality. That is, the complete surplus is divided by agents 1 to $i-1$. Therefore:

$$
\sum_{k=2}^{i-1}\left(x_{k}^{\prime}-x_{k}\right) \leq \sum_{k=1}^{i-1}\left(x_{k}^{\prime}-x_{k}\right)=\left(e_{i}^{\prime}-e_{i}\right)-\left(E_{i}^{\prime}-E_{i}\right) .
$$

Hence, $x_{1}^{\prime} \geq x_{1}$. Because $x_{1}^{\prime} \geq x_{1}$, the surplus to be divided by agents 2 to $i-1$ is now $\left(e_{i}^{\prime}-e_{i}\right)-\left(E_{i}^{\prime}-E_{i}\right)-\left(x_{1}^{\prime}-x_{1}\right)$.

For $j=2$ we can thus establish that:

$$
\sum_{k=3}^{i-1}\left(x_{k}^{\prime}-x_{k}\right) \leq \sum_{k=2}^{i-1}\left(x_{k}^{\prime}-x_{k}\right)=\left(e_{i}^{\prime}-e_{i}\right)-\left(E_{i}^{\prime}-E_{i}\right)-\left(x_{1}^{\prime}-x_{1}\right) .
$$

Hence, $x_{2}^{\prime} \geq x_{2}$. 
This argument can be repeated to find that $x_{j}^{\prime} \geq x_{j}, \forall j<i$. It follows that $e_{i}^{\prime} \geq$ $e_{i} \Rightarrow F\left(\omega^{\prime}\right) \geq F(\omega)$.

\section{(c) Scale Invariance ${ }^{\star}$}

We have to prove that Scale invariance of a bankruptcy rule implies Scale invariance ${ }^{\star}$ of its corresponding sequential sharing rule.

Consider a river sharing problem $\omega=\langle N, e, c\rangle$, and a related problem $\omega^{\prime}=$ $\langle N, \lambda e, \lambda c\rangle$, with $\lambda>0$. In reduced problem $\omega_{i}$, by Scale invariance we obtain $E_{i}^{\prime}=\lambda\left(\sum_{j=1}^{i-1}\left(e_{j}-x_{j}\right)+e_{i}\right)=\lambda E_{i}$. Again, by Scale Invariance this implies that $x_{i}^{\prime}=\lambda x_{i}$ (and $x_{D_{i}}^{\prime}=\lambda x_{D_{i}}$ ). It follows that $F\left(\omega^{\prime}\right)=\lambda F(\omega)$.

\section{(d) Consistency ${ }^{\star}$}

We have to prove that Claims Monotonicity and Resource Monotonicity of a bankruptcy rule imply Consistency ${ }^{\star}$ of its corresponding sequential sharing rule for some feasible and efficient endowments vector $e^{\prime}$.

Consider a river sharing problem $\omega=\langle N, e, c\rangle$, and a related problem $\omega^{\prime}=$ $\left\langle N^{\prime}, e^{\prime}, c^{\prime}\right\rangle$ such that $N^{\prime}=N \backslash\{j\}, c^{\prime}=c \backslash\left\{c_{j}\right\}$, and $e^{\prime}=\left(e_{1}^{\prime}, \ldots, e_{j-1}^{\prime}, e_{j+1}^{\prime}, \ldots, e_{n}^{\prime}\right)$. Denote by $\Delta e_{i}=e_{i}^{\prime}-e_{i} \forall i \in N^{\prime}$ the difference in endowments to agent $i$ between $e$ and $e^{\prime}$. Feasibility requires $\sum_{i \leq k} \Delta e_{i} \leq 0 \forall k<j$. Efficiency requires $\sum_{k \in N^{\prime}} \Delta e_{k}=e_{j}-x_{j}$.

To prove the proposition, we show how to construct the vector difference $\Delta e$, first for the case where $j=1$ and then for the case where $j \geq 2$. Note that excess downstream claims may be lower in $\omega^{\prime}$ than in $\omega$. Using (2), we have $c_{D_{i}}^{\prime}=c_{D_{i}}-c_{j}+$ $e_{j}-\sum_{k=i+1}^{j+1} \Delta e_{k} \forall i \leq j-1$, so that $c_{D_{i}}^{\prime} \leq c_{D_{i}} \forall i \leq j-1$.

Suppose $j=1$. By construction, $x_{1} \leq e_{1}$, so we can set $\Delta e_{2}=e_{1}-x_{1}$. This gives $E_{2}^{\prime}=e_{2}+e_{1}-x_{1}=E_{2}$, while satisfying efficiency and feasibility, and we are done.

Suppose $j \geq 2$. Consider the reduced problem $\omega_{1}^{\prime}$. We have $E_{1}^{\prime}=e_{1}+\Delta e_{1} \leq E_{1}$. Because $c_{D_{1}}^{\prime} \leq c_{D_{1}}$, by Claims Monotonicity and Resource Monotonicity there exists $\Delta e_{1} \leq 0$ such that $x_{1}^{\prime}=x_{1}$. Using this value of $\Delta e_{1}$, we have $x_{D_{1}}^{\prime}=x_{D_{1}}+\Delta e_{1}$.

Now, consider the reduced problem $\omega_{2}^{\prime}$. We have $E_{2}^{\prime}=e_{2}+\Delta e_{2}+x_{D_{1}}^{\prime}=e_{2}+$ $\Delta e_{2}+x_{D_{1}}+\Delta e_{1}$, and because of feasibility $\Delta e_{2} \leq-\Delta e_{1}$, such that $E_{2}^{\prime} \leq E_{2}$. Because $c_{D_{2}}^{\prime} \leq c_{D_{2}}$, by Claims Monotonicity and Resource Monotonicity there exists $\Delta e_{2} \leq-\Delta e_{1}$ such that $x_{2}^{\prime}=x_{2}$. Using this value of $\Delta e_{2}$, we have $x_{D_{2}}^{\prime}=x_{D_{2}}+\Delta e_{2}$.

The same argument can be repeated up to and including reduced problem $\omega_{j-1}^{\prime}$.

Now, consider reduced problem $\omega_{j+1}^{\prime}$. We have:

$$
\begin{aligned}
E_{j+1}^{\prime} & =e_{j+1}+\Delta e_{j+1}+x_{D_{j-1}}^{\prime} \\
& =e_{j+1}+\Delta e_{j+1}+\sum_{k \leq j-1}\left(e_{k}-x_{k}+\Delta e_{k}\right) .
\end{aligned}
$$


We can set $\Delta e_{j+1}=e_{j}-x_{j}-\sum_{k \leq j-1}\left(\Delta e_{k}\right)$. This gives:

$$
E_{j+1}^{\prime}=e_{j+1}+e_{j}-x_{j}+\sum_{k \leq j-1}\left(e_{k}-x_{k}\right)=E_{j+1}
$$

while satisfying efficiency and feasibility and we are done.

\section{Proof of Proposition 3}

Proof We prove each part of the proposition separately.

\section{Part (a)}

By Proposition 1, a sharing rule satisfies Only n's Excess Claim Matters, No Advantageous Downstream Merging and Upstream Consistency if and only if it is a sequential sharing rule. We therefore have to verify that a sequential sharing rule satisfies Location Monotonicity if and only if it is based on PRO.

First we show that the sequential sharing rule based on PRO satisfies Location Monotonicity. Recall from Definition 2 and the definition of PRO that $x_{i}=\lambda c_{i}$ with $\lambda=p_{i}=E_{i} /\left(c_{i}+c_{D_{i}}\right)$. We first show that Location Monotonicity is satisfied for agents $i$ and $i+1$. We do so by contradiction. Suppose that $c_{i}=c_{i+1}$ but $F_{i}(\omega)>$ $F_{i+1}(\omega)$ so that $p_{i}>p_{i+1}$. Then we have $E_{i} /\left(c_{i}+c_{D_{i}}\right)>E_{i+1} /\left(c_{i+1}+c_{D_{i+1}}\right)$. Substituting $E_{i+1}=E_{i}+e_{i+1}-x_{i}$ and $x_{i}=c_{i} E_{i} /\left(c_{i}+c_{D_{i}}\right)$, and re-ordering terms gives:

$$
c_{i+1}+c_{D_{i+1}}>\frac{\left(c_{i}+c_{D_{i}}\right)\left(E_{i}+e_{j}\right)}{E_{i}}-c_{i} .
$$

Substituting $c_{i+1}+c_{D_{i+1}}=c_{D_{i}}+e_{j}$, re-ordering, and cancelling terms gives $E_{i}>$ $c_{i}+c_{D_{i}}$, which contradicts Lemma 1 . By transitivity of the order of agents, Location Monotonicity is also satisfied for agents $i$ and $i+k \forall k>1$ when $c_{i}=c_{i+k}$.

Next we show that any sequential sharing rule that satisfies Location Monotonicity is based on PRO. Consider river sharing problem $\omega=\langle N, e, c\rangle$ and any two agents $i, j \in N$ such that $i<j$ and $c_{i}=c_{j}$. By Location Monotonicity we have $F_{i}(\omega) \leq F_{j}(\omega)$ so that given equal claims $p_{i} \leq p_{j}$. Because the property holds for any two agents with equal claims, this implies, using (2), that

$$
\frac{x_{i}}{c_{i}} \leq \frac{\sum_{j \in D_{i}} x_{j}}{\sum_{j \in D_{i}} c_{j}}=\frac{x_{D_{i}}}{c_{D_{i}}+\sum_{j \in D_{i}} e_{j}} \Longrightarrow \frac{x_{i}}{c_{i}} \leq \frac{x_{D_{i}}}{c_{D_{i}}}
$$

Substituting $x_{D_{i}}=E_{i}-x_{i}$ and re-ordering terms gives

$$
x_{i} \leq \frac{c_{i}}{c_{i}+c_{D_{i}}} E_{i}
$$


In words, the allocation to agent $i$ is weakly smaller than the allocation provided by PRO. By the efficiency requirement (b) of Definition 2, this implies that $x_{D_{i}}$ is weakly larger than the allocation provided by PRO. By the anonymity requirement (c) of Definition 5, we know that the reverse is also true for both $x_{i}$ and $x_{D_{i}}$. Hence, (A3) holds with equality, which is equivalent to the definition of PRO. This completes the proof of part (a).

\section{$\operatorname{Part}(b)$}

By Proposition 1, a sharing rule satisfies Only n's Excess Claim Matters, No Advantageous Downstream Merging and Upstream Consistency if and only if it is a sequential sharing rule. We therefore have to verify that a sequential sharing rule satisfies Bankruptcy Equivalence if and only if it is based on PRO.

First we show that the sequential sharing rule based on PRO satisfies Bankruptcy Equivalence. This part of the proof is by induction. Recall from Definition 2 and the definition of PRO that $x_{i}=\lambda c_{i}$ with $\lambda=p_{i}=E_{i} /\left(c_{i}+c_{D_{i}}\right)$. For $i=1$ we have $p_{1}=\frac{e_{1}}{c_{1}+c_{D_{1}}}=\frac{e_{1}}{\sum_{j \in N} c_{j}}$ so that $F_{1}(\omega)=B_{1}(\psi)$. The inductive step is to show that $p_{i}=p_{i+1}$. We have (i) $x_{D_{i}}=\frac{E_{i}}{c_{i}+c_{D_{i}}} c_{D_{i}}$. Because $e_{i}=0 \forall i>1$, by (1) we have (ii) $E_{i+1}=x_{D_{i}}$, and by (2) we have (iii) $c_{D_{i}}=c_{i+1}+c_{D_{i+1}}$. Combining (ii) and (iii), we have (iv) $p_{i+1}=\frac{E_{i+1}}{c_{i+1}+c_{D_{i+1}}}=\frac{x_{D_{i}}}{c_{D_{i}}}$. Combining (i) and (iv), we obtain $p_{i+1}=\frac{E_{i}}{c_{i}+c_{D_{i}}}=p_{i}$ so that $F_{i}(\omega)=B_{i}(\psi) \forall i \in N$. Hence, the sequential sharing rule based on PRO satisfies Bankruptcy Equivalence.

Next we show that any sequential sharing rule that satisfies Bankruptcy Equivalence is based on PRO. Consider a river sharing problem with symmetric claims $c$ such that $\omega^{s}=\left\langle N,\left(e_{1}, 0, \ldots, 0\right),(c, \ldots, c)\right\rangle$, and a sequential sharing rule $F$. Now, consider a related problem $\omega^{r}=\left\langle K,\left(e_{1}, 0, \ldots, 0\right),\left(c, \frac{n-1}{k-1} c, \ldots, \frac{n-1}{k-1} c\right)\right\rangle$, with $n=|N| \neq k=|K|$. By construction, $\omega^{s}$ and $\omega^{r}$ have the same reduced game $\omega_{1}=\left\langle\left\{1, D_{1}\right\},\left(e_{1}, 0\right),\left(c, c_{D_{1}}\right\rangle\right.$ such that $c_{D_{1}}=(n-1) c_{i}=\frac{n-1}{k-1}(k-1) c_{j}$. Let $x_{1}=F_{1}\left(\omega_{1}^{s}\right)=F_{1}\left(\omega_{1}^{r}\right)$. Because $F$ is a sequential sharing rule, we also know that $x_{1}=F_{1}\left(\omega^{s}\right)=F_{1}\left(\omega^{r}\right)$. By Bankruptcy Equivalence, because of symmetric claims, and by the anonymity requirement (c) of Definition 5 we have $F_{1}\left(\omega^{s}\right)=\cdots=$ $F_{n}\left(\omega^{s}\right)=\frac{1}{n} e_{1}$. For the same reason we must have $F_{2}\left(\omega^{r}\right)=\cdots=F_{n}\left(\omega^{r}\right)$ and for $F_{2}\left(\omega^{r}\right)$ we obtain $F_{2}\left(\omega^{r}\right)=\left(e_{1}-x_{1}\right) \frac{1}{k-1}$. Substituting $x_{1}=\frac{1}{n} e_{1}$ we have $F_{2}\left(\omega^{r}\right)=$ $\frac{n-1}{n} \frac{1}{k-1} e_{1}=\left(\frac{n-1}{k-1}\right) \frac{1}{n} e_{1}$ and $F_{2}\left(\omega^{r}\right)$ must be proportional to claims. This argumentation can be repeated for any agent $j=\alpha+1$ with any claim $c^{\prime}=\frac{n-\alpha}{k-\alpha} c$ by constructing an appropriate related game $\omega^{r^{\prime}}=\left\langle K,\left(e_{1}, 0, \ldots, 0\right),\left(c, \ldots, c, \frac{n-\alpha}{k-\alpha} c \ldots, \frac{n-\alpha}{k-\alpha} c\right)\right\rangle$. This completes the proof of part (b).

Acknowledgments We thank an anonymous associate editor and referee for stimulating comments. We also thank Harold Houba, Carmen Marchiori, Arjan Ruijs, Ivan Soraperra and Dirk Van de gaer for providing comments on earlier versions of this paper. Part of this research was done while the first author was visiting the Department of Economics at Queen Mary, University of London. 
Open Access This article is distributed under the terms of the Creative Commons Attribution Noncommercial License which permits any noncommercial use, distribution, and reproduction in any medium, provided the original author(s) and source are credited.

\section{References}

Ambec S, Ehlers L (2008) Sharing a river among satiable agents. Games Econ Behav 64(1):35-50

Ambec S, Sprumont Y (2002) Sharing a river. J Econ Theory 107(2):453-462

Ansink E, Ruijs A (2008) Climate change and the stability of water allocation agreements. Environ Resour Econ 41(2):249-266

Ansink E, Weikard H-P (2009) Contested water rights. Eur J Political Econ 25(2):247-260

Arrow K, Dasgupta P, Goulder L, Daily G, Ehrlich P, Heal G, Levin S, Mäler K-G, Schneider S, Starrett D, Walker B (2004) Are we consuming too much? J Econ Perspect 18(3):147-172

Aumann RJ, Maschler M (1985) Game theoretic analysis of a bankruptcy problem from the Talmud. J Econ Theory 36(2):195-213

Bergantiños G, Sanchez E (2002) The proportional rule for problems with constraints and claims. Math Soc Sci 43(2):225-249

Bjørndal E, Jörnsten K (2010) Flow sharing and bankruptcy games. Int J Game Theory 39(1-2):11-28

Bossert W, Fleurbaey M (1996) Redistribution and compensation. Soc Choice Welf 13(3):343-355

Branzei R, Ferrari G, Fragnelli V, Tijs S (2008) A flow approach to bankruptcy problems. AUCO Czech Econ Rev 2(2):146-153

Carraro C, Marchiori C, Sgobbi A (2007) Negotiating on water: insights from non-cooperative bargaining theory. Environ Dev Econ 12(2):329-349

Coram A (2006) The optimal allocation of water along a system of rivers: a continuous model with sequential bidding. Aust J Agric Resour Econ 50(3):313-326

Daoudy M (2008) Hydro-hegemony and international water law: laying claims to water rights. Water Policy 10(S2):89-102

Dasgupta P, Mäler K-G, Barrett S (1999) Intergenerational equity, social discount rates, and global warming. In: Portney PR, Weyant JP (eds) Discounting and intergenerational equity. Resources for the future, Washington, DC, pp 51-77

Davidson MD (2008) Wrongful harm to future generations: the case of climate change. Environ Values 4(17):471-488

Fleurbaey M (1994) On fair compensation. Theory Decis 36(3):277-307

Goetz RU, Martinez Y, Rodrigo J (2008) Water allocation by social choice rules: the case of sequential rules. Ecol Econ 65(2):304-314

Herings PJ-J, Predtetchinski A (2007) Sequential share bargaining. METEOR Research Memorandum 07/005, Maastricht University

Herings PJ-J, Van der Laan G, Talman D (2007) The socially stable core in structured transferable utility games. Games Econ Behav 59(1):85-104

Herrero C, Villar A (2001) The three musketeers: four classical solutions to bankruptcy problems. Math Soc Sci 42(3):307-328

Houba H (2008) Computing alternating offers and water prices in bilateral river basin management. Int Game Theory Rev 10(3):257-278

İlkiliç R., Kayı C. (2009) Allocation rules on networks. Paper presented at the 14th Coalition Theory Network Workshop in Maastricht, the Netherlands

Khmelnitskaya AB (2010) Values for rooted-tree and sink-tree digraph games and sharing a river. Theory Decis 69(4):657-669

Klaus B, Peters H, Storcken T (1997) Reallocation of an infinitely divisible good. Econ Theory 10(2): 305-333

Moreno-Ternero JD, Villar A (2006) New characterizations of a classical bankruptcy rule. Rev Econ Des 10(2):73-84

Moulin H (2000) Priority rules and other asymmetric rationing methods. Econometrica 68(3):643-684

Moulin H (2002) Axiomatic cost and surplus-sharing. In: Arrow K, Sen AK, Suzumura K (eds) Handbook of social choice and welfare. Elsevier, Amsterdam, pp 289-357

O’Neill B (1982) A problem of rights arbitration from the Talmud. Math Soc Sci 2(4):345-371 
Parrachino I, Dinar A, Patrone F (2006) Cooperative game theory and its application to natural, environmental and water resource issues: application to water resources. World Bank Policy Research Working Paper 4074

Salman SMA (2007) The Helsinki Rules, the UN Watercourses Convention and the Berlin Rules: perspectives on international water law. Int J Water Resour Dev 23(4):625-640

Thomson W (2003) Axiomatic and game-theoretic analysis of bankruptcy and taxation problems: a survey. Math Soc Sci 45(3):249-297

Van den Brink R, Van der Laan G, Vasil'ev V (2007) Component efficient solutions in line-graph games with applications. Econ Theory 33(2):349-364

Weikard H-P (2004) Who should receive the $\mathrm{CO}_{2}$ emission permits? In: Döring R, Rühs M (eds) Ökonomische Rationalität und Praktische Vernunft: Gerechtigkeit, Ökologische Ökonomie und Naturschutz. Königshausen und Neumann, Würzburg, pp 71-82

Wolf AT (1999) Criteria for equitable allocations: the heart of international water conflict. Nat Resour Forum 23(1):3-30

Young HP (1987) On dividing an amount according to individual claims or liabilities. Math Oper Res 12(3):398-414 